\title{
Transverse colonic volvulus due to mesenteric fibromatosis: a case report
}

\author{
Akihiro Yoshida ${ }^{1,2^{*}}$, Yasutake Uchima ${ }^{3}$, Naoki Hosaka ${ }^{4}$, Kosuke Minaga $^{2}$ and Masatoshi Kudo ${ }^{2}$
}

\begin{abstract}
Background: Colonic volvulus, a condition in which a colonic segment partially twists around its base, is the third leading cause of large bowel obstruction after colonic neoplasms and diverticular disease. However, volvulus of the transverse colon is the rarest type of large intestinal volvulus. Moreover, the occurrence of transverse colonic volvulus secondary to a benign tumor originating from outside the intestine has never been reported. We hereby report a case of transverse colonic volvulus caused by mesenteric fibromatosis.

Case presentation: A 53-year-old female with a history of rheumatoid arthritis and thyroid tumor presented with abdominal pain for 1 day. Abdominal computed tomography revealed intestinal torsion at the hepatic flexure. Twisted and obstructed mucosa of the transverse colon was observed during colonoscopy, but no tumor invasion of the mucosal surface was detected. A solid mass of a mesenteric origin with involvement of the transverse colon was observed during surgery. The mass was diagnosed surgically as transverse colonic volvulus induced by a mesenteric tumor. Hence, the patient underwent a right hemicolectomy. Histopathological results indicated mesenteric desmoid-type fibromatosis. The postoperative recovery was uneventful, and the patient was discharged 8 days after surgery.
\end{abstract}

Conclusions: Although mesenteric fibromatosis is rare, this disease should be considered when managing transverse colonic volvulus resulting from nonmucosal tumors.

Keywords: Mesenteric fibromatosis, Transverse colonic volvulus, Desmoid tumor, Right hemicolectomy

\section{Background}

Colonic volvulus is a rotation or twisting of the large intestine around its vascular pedicle [1]. According to case descriptions in the literature, it most commonly involves the sigmoid colon $(60-70 \%)$, followed by the cecum (25-40\%), and the transverse colon (1-4\%) [2]. Thus, volvulus is rarely observed in the transverse colon compared to other colonic segments. A major cause of colonic volvulus is the presence of a redundant mobile colon with a narrow mesenteric root base [3]. Other predisposing factors for colonic volvulus include a high-fiber diet, constipation, previous abdominal surgery, colonic

\footnotetext{
*Correspondence: ackiy0409@gmail.com

1 Department of Gastroenterology, Fuchu Hospital, Izumi, Japan

Full list of author information is available at the end of the article
}

neoplasm, pregnancy, and neurological and psychiatric diseases [2-4]. Reports of intestinal obstruction due to mesenteric fibromatosis (MF) are rare $[5,6]$, and no cases of transverse colonic volvulus due to MF have been reported. We herein report a case of transverse colonic volvulus secondary to MF in a 53-year-old female.

\section{Case presentation}

A 53-year-old female with a history of rheumatoid arthritis and thyroid tumor was referred to our hospital. The patient's chief complaint was abdominal pain for 1 day, and she had no history of abdominal surgery or trauma. Upon admission, she had right abdominal tenderness. Blood tests showed unremarkable results (white blood cell count, $4800 / \mu \mathrm{L}$; red blood cell count, $4.78 \times 10^{6} /$ $\mu \mathrm{L}$; hemoglobin, $14.8 \mathrm{~g} / \mathrm{dL}$; hematocrit, $43.7 \%$; platelets, 


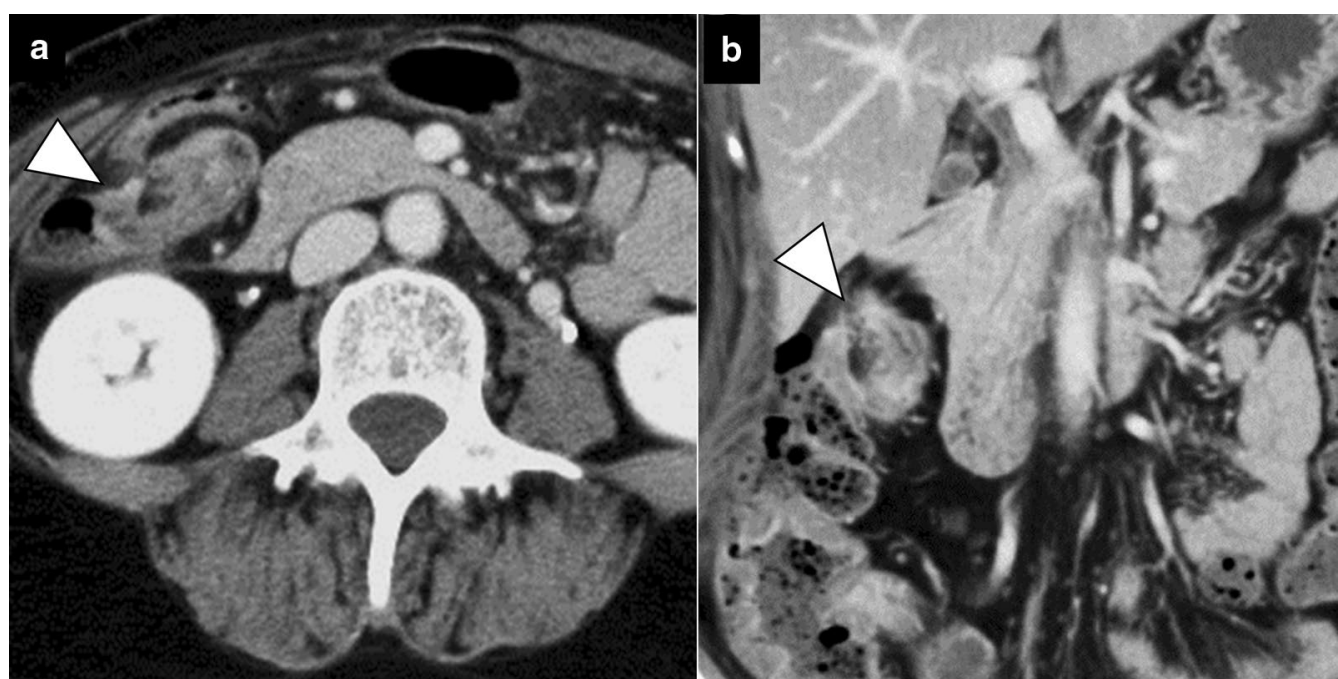

Fig. 1 Contrast-enhanced computed tomography showing intestinal torsion at the hepatic flexure (arrowheads) (a; axial image, b; coronal image)

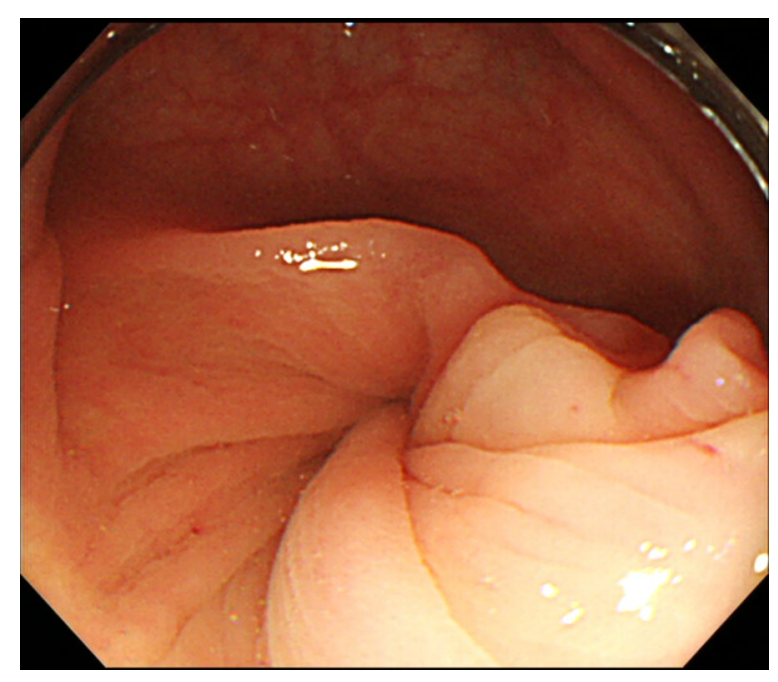

Fig. 2 Colonoscopy showing twisted mucosal folds in the transverse colon. No obvious neoplastic change was noted on the mucosal surface

$20.7 \times 10^{4} / \mu \mathrm{L} ;$ C-reactive protein, $0.59 \mathrm{mg} / \mathrm{dL}$; creatine kinase, $50 \mathrm{U} / \mathrm{L}$; carcinoembryonic antigen, $2.0 \mathrm{ng} / \mathrm{mL}$; and carbohydrate antigen 19-9, $12 \mathrm{U} / \mathrm{mL})$. Contrastenhanced computed tomography (CT) revealed intestinal torsion at the hepatic flexure (Fig. 1). A colonoscopy was performed to evaluate the cause of the intestinal torsion, which revealed twisted mucosal folds in the transverse colon but no obvious neoplastic change on the mucosal surface (Fig. 2). The scope could not be advanced past the torsion of the transverse colon, making it impossible to observe the superior colon.

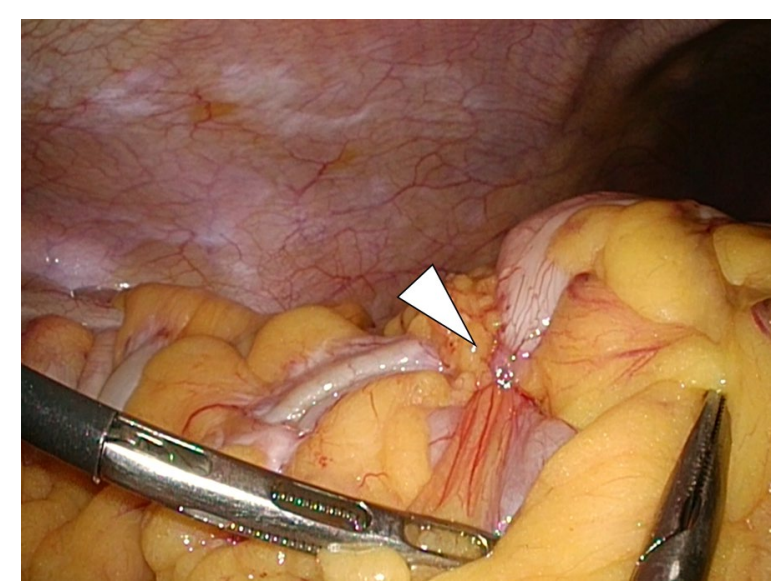

Fig. 3 Surgical finding. The tumor was intraoperatively found to have arisen from the mesentery, causing a rotation of the transverse colon around itself (arrowhead)

Based on these findings, the differential diagnosis included gastrointestinal stromal tumor, malignant lymphoma, sarcoma, carcinoid, and mesenteric tumors. Surgery was performed to release the transverse colonic volvulus and establish a definitive diagnosis. The lesion arose from the mesentery, causing a $180^{\circ}$ clockwise rotation of the transverse colon around itself (Fig. 3). The surgical diagnosis was transverse colonic volvulus due to a tumor of a mesenteric origin. Consequently, a right hemicolectomy with lymphadenectomy was performed.

Macroscopically, the tumor was a clearly demarcated solid mass with a white-gray appearance (Fig. 4). Histologically, the tumor consisted of dense collagenous fibers and a complicated proliferation of spindle-shaped cells, 


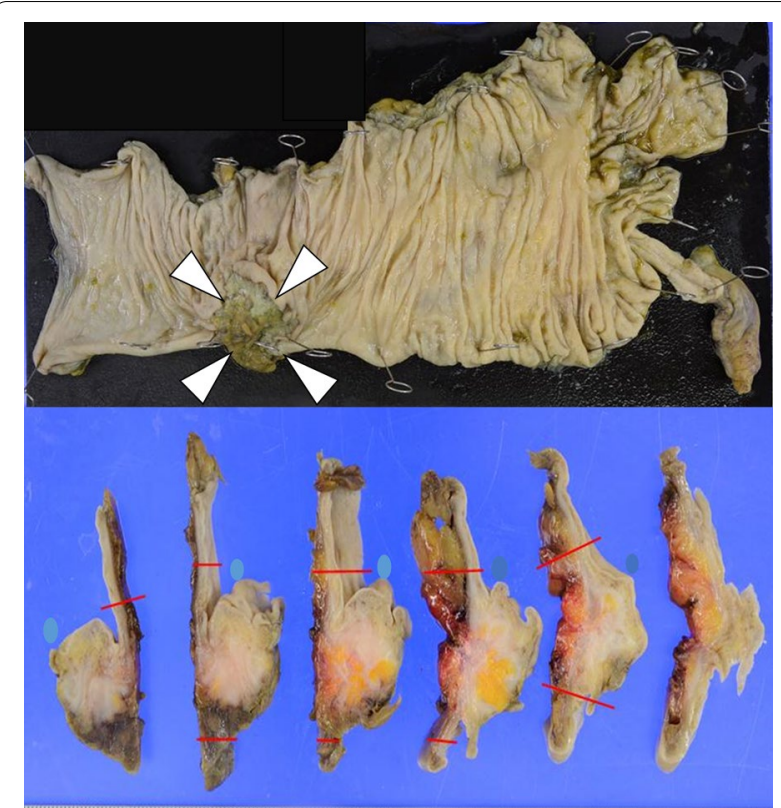

Fig. 4 Macroscopic findings. The tumor was a clearly demarcated solid mass with a white-gray appearance

which generally appeared heterozygous and homogeneous, yet occasionally exhibited nuclear enlargement and mismatch in the center of the tumor (Fig. 5). The tumor cells were positive for vimentin but negative for S100 protein, synaptophysin, cluster of differentiation 34, c-kit, and DOG-1, based on the immunohistochemical findings (Fig. 5). These pathological findings led us to the final diagnosis of MF. The patient had an uneventful postoperative course and was eventually discharged in good condition 8 days after surgery. She is currently well and shows no signs of recurrence 6 months after the surgery.

\section{Discussion and conclusions}

MF, also referred to as desmoid fibromatosis, was first described by Muller in 1838 [7]. The annual incidence of MF is only 2-4 per million, accounting for $3 \%$ of all soft tissue tumors [8]. MF originates from the mesenchymal tissue and is a type of intra-abdominal fibromatosis, comprising nearly $8 \%$ of all fibromatoses. MF has a low morbidity rate $[8,9]$. The etiology of MF includes trauma, surgery, hormones, and heredity [7, 9-11]. Furthermore, MF is associated with familial adenomatous polyposis and is a component of Gardner's syndrome [12, 13]. Fibromatoses can occur almost anywhere in the body and are classified according to their anatomic locations into the following three main categories: extra-abdominal (trunk and extremities), along the abdominal wall, and, least commonly, intra-abdominal. The mesentery is the most probable location for an intra-abdominal desmoid tumor. MF is a fibroblastic growth of the mesentery that occurs either spontaneously or as a result of surgical trauma. MF develops most frequently in the intestinal mesentery, followed by the omentum and mesocolon [14].

The features of intra-abdominal desmoid tumors shown by $\mathrm{CT}$ and magnetic resonance imaging (MRI) are related to their histological characteristics and vascularity. Although the CT findings are nonspecific, intra-abdominal desmoid tumors typically appear as well-delineated

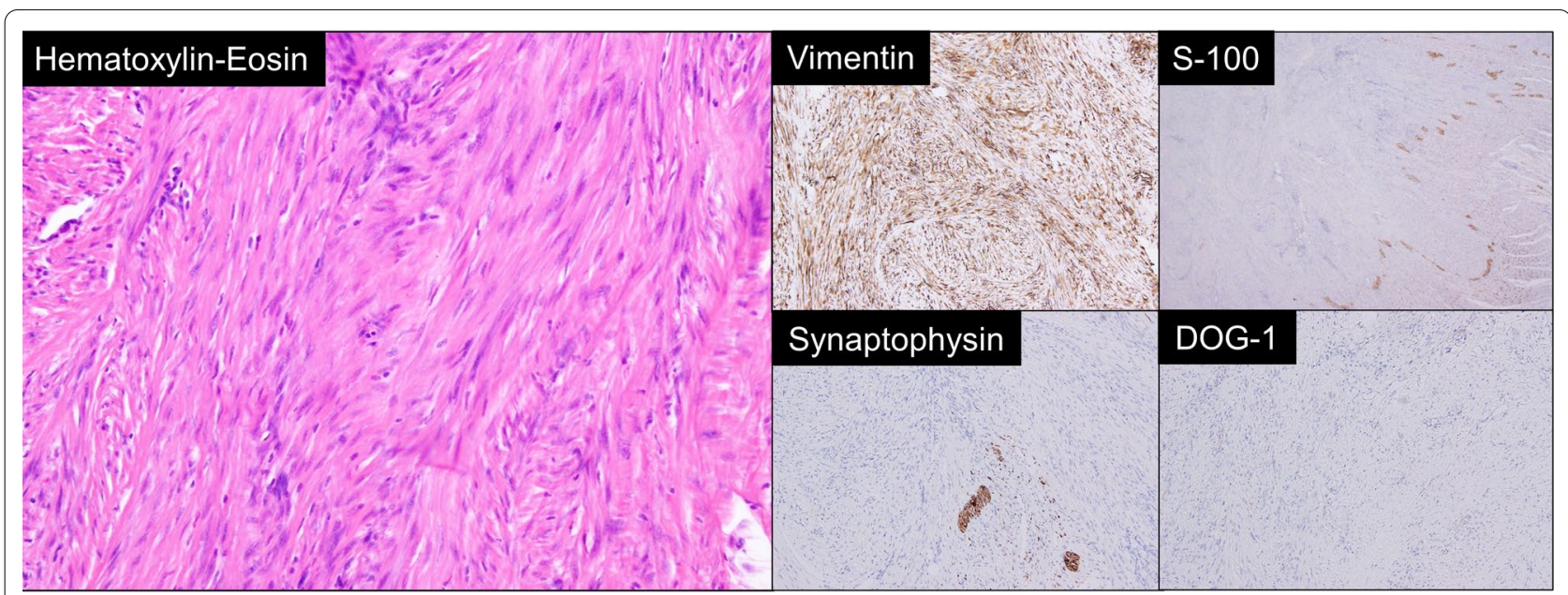

Fig. 5 Microscopic findings. Hematoxylin and eosin stain; the tumor consisted of dense collagenous fibers and a complicated proliferation of spindle-shaped cells, which generally appeared heterozygous and homogenous, yet occasionally exhibited nuclear enlargement and mismatch in the center of the tumor. Immunohistochemical stain; the tumor cells were positive for vimentin but negative for S100 protein, synaptophysin, and DOG-1 
solid soft tissue masses without calcifications [15]. The signal intensity of MF on MRI reflects the proportion of collagen fibers, spindle cells, and extracellular matrix present [16]. MF most commonly presents heterogeneously with hypo-/hyperintense signals on T2 images and iso-/ hypointense signals on T1 images [16, 17]. The hypointense non-enhancing linear bands, presumably representing dense collagen stroma, are characteristic findings on all MRI sequences [17]. For MF diagnosis, the value of diffusion-weighted MRI sequences is unclear $[17,18]$.

MF is pathologically characterized by a well-differentiated proliferation of fibroblasts, the presence of intercellular collagen fibers, poor cell heteromorphism, the absence of the nuclear fission image, invasive development, and no distant metastasis but local recurrence [19]. Although not pathognomonic of desmoid tumors, spindle cells are common histopathological findings. The immunohistochemical characteristics of mesenteric desmoid tumors include positive staining for vimentin and $\beta$-catenin but negative staining for smooth muscle actin, S100, CD117, and CD34 [20].

For symptomatic tumors or tumors that impair function, decisions on the form of therapy should be made after careful consideration of the tumor location and the potential morbidity of the therapeutic option. Surgical resection with negative margins has traditionally been regarded as the mainstay of therapy for abdominal wall and intra-abdominal MF. Nevertheless, recent insights into the natural history of MF have led to a paradigm shift from margin-negative resection to the acceptance of microscopically positive resection or observation with surgery used more selectively [21]. Other treatment options include radiation therapy and systemic medication therapy with the following choices: tamoxifen, which is believed to induce growth suppression in desmoid tumors through interaction with estrogen receptor beta on tumor cells; nonsteroidal anti-inflammatory drugs, such as sulindac; and doxorubicin and methotrexate, with vinca alkaloid-based chemotherapy [22]. MF has a local recurrence rate of $22.2 \%$ following curative resection [23]. Thus, clinically and radiographic follow-up of patients should be performed biannually for at least 3 years and then annually [24].

To the best of our knowledge, this is the first report of a case of intestinal volvulus secondary to MF. The current study underscores the fact that MF should be considered as a possible cause of intestinal volvulus. In conclusion, although observed seldomly in clinical practice, MF may lead to intestinal volvulus. Therefore, MF should be considered as a potential cause when encountering cases of transverse colonic volvulus with no apparent tumor derived from the intestinal mucosa.
Abbreviations

CT: Computed tomography; MF: Mesenteric fibromatosis.

\section{Acknowledgements}

We thank James T and Twyla H from Enago Group (https://www.enago.jp) for editing a draft of this manuscript.

\section{Authors' contributions}

$A Y$ and $Y U$ took care of the patient. AY, YU and MK contributed to the study conception and design. AY and KM contributed to critical revisions to the manuscript. NH performed pathological examinations. All the authors listed read and approved the manuscript prior to submission, including the names and order of the authors. All authors read and approved the final manuscript.

Funding

No sources of funding were declared for this study.

Availability of data and materials

Data sharing does not apply to this article because no datasets were generated or analyzed during the current study.

\section{Ethics approval and consent to participate}

This study conformed to the ethical guidelines of the 1975 Declaration of Helsinki and was approved by the Institutional Review Board of the Fuchu Hospital.

\section{Consent for publication}

The patient has consented to the submission of the case report to the journal. The patient gave a written consent for her personal or clinical details along with any identifying images to be published in this case report.

\section{Competing interests}

The authors declare that they have no competing interests.

\section{Author details}

${ }^{1}$ Department of Gastroenterology, Fuchu Hospital, Izumi, Japan. ${ }^{2}$ Department of Gastroenterology and Hepatology, Kindai University Faculty of Medicine, Osaka-Sayama, Osaka 589-8511, Japan. ${ }^{3}$ Department of Surgery, Fuchu Hospital, Izumi, Japan. ${ }^{4}$ Department of Pathology, Fuchu Hospital, Izumi, Japan.

Received: 3 September 2020 Accepted: 21 December 2020

Published online: 06 January 2021

\section{References}

1. Motsumi MJ, Tlhomelang O. Synchronous volvulus of the sigmoid and transverse colon in a 26-year-old male. J Surg Case Rep. 2018;11:rjy295.

2. Perrot L, Fohlen A, Alves A, Lubrano J. Management of the colonic volvulus in 2016. J Visc Surg. 2016;153:183-92.

3. Mulas C, Bruna M, García-Armengol J, Roig JV. Management of colonic volvulus. Experience in 75 patients. Rev Esp Enferm Dig. 2010;102:239-48.

4. Ndong A, Diao ML, Tendeng JN, Diallo AC, Ma Nyemb PM, Konaté I. Synchronous sigmoid and transverse volvulus: a case report and qualitative systematic review. Int J Surg Case Rep. 2020;75:297-301.

5. Holubar S, Dwivedi AJ, O'Connor J. Giant mesenteric fibromatosis presenting as small bowel obstruction. Am Surg. 2006;72:427-9.

6. Venkat D, Levine E, Wise WE. Abdominal pain and colonic obstruction from an intra-abdominal desmoid tumor. Gastroenterol Hepatol. 2010;6:662-5

7. Polat C, Aktepe F, Turel S, Yazicioglu B, Ozkececi T, Arikan Y. A giant mesenteric fibromatosis case presenting with mechanical intestinal obstruction and successfully resected with partial duodeno-jejunectomy and right hemicolectomy. Clinics (Sao Paulo). 2010;65:110-3.

8. Sakorafas GH, Nissotakis C, Peros G. Abdominal desmoid tumors. Surg Oncol. 2007:16:131-42.

9. Batori M, Chatelou E, Mariotta G, Sportelli G, Pastore P, Casella G, et al. Giant mesenteric fibromatosis. Eur Rev Med Pharmacol Sci. 2005:9:223-5.

10. Sinukumar S, Gomes RM, Kumar RK, Desouza A, Saklani A. Sporadic giant mesenteric fibromatosis. Indian J Surg Oncol. 2014;5:242-5. 
11. Chaudhary P. Mesenteric fibromatosis. Int J Colorectal Dis. 2014;29:1445-51.

12. Galletto P, Leoz ML, Castells A, Balaguer F. Tumores desmoides intraabdominales en la poliposis adenomatosa familiar [Intraabdominal desmoid tumors in familial adenomatous polyposis]. Gastroenterol Hepatol. 2013;36:580-6.

13. Park JH, Yagerman S, Feng H, Kim RH, Meehan SA, Lewin J. Gardnerdiamond syndrome. Dermatol Online J. 2016;22:48-50.

14. Burke AP, Sobin LH, Shekitka KM, Federspiel BH, Helwig EB. Intra-abdominal fibromatosis. A pathological analysis of 130 tumors with comparison of clinical subgroups. Am J Surg Pathol. 1990;14:335-41.

15. Chen CB, Chiou YY, Chen CH, Chou YH, Chiang JH, Chang CY. Sonographic and computed tomography findings of intra-abdominal desmoid tumor. J Chin Med Assoc. 2010;73:393-5.

16. Lee JC, Thomas JM, Phillips S, Fisher C, Moskovic E. Aggressive fibromatosis: MRI features with pathologic correlation. AJR Am J Roentgenol. 2006;186:247-54.

17. Braschi-Amirfarzan M, Keraliya AR, Krajewski KM, Tirumani SH, Shinagare $A B$, Hornick $J$, et al. role of imaging in management of desmoid-type fibromatosis: a primer for radiologists. Radiographics. 2016:36:767-82.

18. Abd-El Khalek Abd-ALRazek A, Fahmy DM. Diagnostic value of diffusionweighted imaging and apparent diffusion coefficient in assessment of the activity of Crohn disease: 1.5 or $3 \mathrm{~T}$. J Comput Assist Tomogr. 2018:42:688-96.
19. Stout AP, Latters R. Tumors of the soft tissues. Atlas of Tumor Pathology, 2nd Series, Fascicle 1, Armed Forces Institute of Pathology. Washington DC; 1967. p. 451-4

20. Jia C, Tian B, Dai C, Wang X, Bu X, Xu F. Idiopathic desmoid-type fibromatosis of the pancreatic head: case report and literature review. World J Surg Oncol. 2014;12:103.

21. Howard JH, Pollock RE. Intra-abdominal and abdominal wall desmoid fibromatosis. Oncol Ther. 2016;4:57-72.

22. Jambhekar A, Robinson S, Zafarani P, Rucinski J, Gudavalli P. Intestinal obstruction caused by desmoid tumours: a review of the literature. JRSM Open. 2018;9.

23. Burke AP, Sobin LH, Shekitka KM, Federspiel BH, Helwig EB. Intra-abdominal fibromatosis. A pathologic analysis of 130 tumors with comparison of clinical subgroups. Am J Surg Pathol. 1990;14:335-41.

24. Venkat D, Levine E, Wise WE. Abdominal pain and colonic obstruction from an intra-abdominal desmoid tumor. Gastroenterol Hepatol (NY). 2010;6:662-5

\section{Publisher's Note}

Springer Nature remains neutral with regard to jurisdictional claims in published maps and institutional affiliations.
Ready to submit your research? Choose BMC and benefit from:

- fast, convenient online submission

- thorough peer review by experienced researchers in your field

- rapid publication on acceptance

- support for research data, including large and complex data types

- gold Open Access which fosters wider collaboration and increased citations

- maximum visibility for your research: over $100 \mathrm{M}$ website views per year

At BMC, research is always in progress.

Learn more biomedcentral.com/submissions 